\title{
Smart Technologies and the Case of People with Disabilities: A Preliminary Overview
}

\author{
Maria POLI ${ }^{\mathrm{a}}$ \\ ${ }^{a}$ Lecturer, Department of Interior Architecture, University of West Attica, Aigaleo, \\ Greece
}

\begin{abstract}
Recently, smart technologies as well as the digitization has entered dynamically into our lives. Cities become mega-cities because of the over population, human health conditions are gradually degraded. The existence of disabled people and the lack of their socialization the diversity of stakeholders as human beings and the difficulty of integrating them into society are few of some problems that Smart City and Smart Technology come to give manageable solutions. Solutions that could find into suggesting researches and intelligence analytics. It is important to refer to this relationship of intelligent capabilities and human resources. This study presents an overview of digital technology especially for people with disabilities. It highlights the contribution of technology to simple everyday habits of disabled and the ability to access the immediate environment. In conclusion, this article is based on the individual requirements, human rights, and preferences of people with disabilities and gives an intriguing perspective to a subject that will be in the limelight and provide effective solutions in the next years driven by technological developments.
\end{abstract}

Keywords. Smart Technology, Smart Cities, Accessibility, Disabled

\section{Introduction}

Nowadays human activities are entering a computerization phase. New tools have emerged, such as e-commerce sites, mobile systems and social media platforms facilitating the communication and development of our standards of living.

This study aims to explore the prospects of: Section 1) Smart Technology and what it consists of. Section 2) The definition of the disability the Disabled people, and their involvement with technology through everyday home devices. Section 3) Disabled people -Technology and Smart Applications. Section 4) Conclusion and Future

The characteristic of the 21 st century society is the rapidly development of technologies information and communication. The technological revolution has an impact to everyday living conditions to our jobs even to our personal behavior. The social and economic changes are based to the rapid increase of the smart technology. For people with disabilities and especially people who needs assistance of another person all the time, technology effects their independence, privacy and autonomy. Providing an accessible life in their familiar surroundings through technology, their autonomy is increasing, their security is enhancing, and isolation is preventing by staying socially connected.

The study investigates the aspects of Smart Applications in relation to persons with disabilities, such as cognitive impairments or kinetic disabilities. Using modern digital 
technological tools, the author provides an overview of a sensitive subject that can be escalated to an established obligation, as well as a glimpse into the future of Smart Cities, which will become a domain of an all-inclusive society regardless of the diversity of people's disabilities.

\section{About Smart Technology}

What is smart technology? Is it the transfer of big data through internet? The connectivity with the Internet? The interconnection between machines and people through sensors and the ability that objects have acquired guide our lives? The existence of smartphones which give the opportunity of sharing personal and professional data? The artificial intelligence? or a combination of all these [1]?

Smart technology includes smart computers / devices with hardware, software and network technologies to be able to provide real-time real-world perception to help people make smarter decisions and provide new business solutions procedures and performance [2]. Artificial Intelligence (Al) is a machine's ability to imitate human cognitive abilities like problem solving and learning [3].

It also involves language, speech and strategic thinking, using basis of algorithmic machine learnings to build systems and find applications close to human factors creating intelligent machines and substituting human activities and functions. The application fields of Al have an enormous impact to important fields of science [4].

Through Internet we have the ability to connect the virtual with the real world. It is the magic tool that connect people with other people, with their work, with companies with public services and keeps all this together [5]. According the concept Internet of Things (IoT) all the objects or devices could be connected with others and identify them based on smart technology [6]. This connection becomes successfully realized through the assimilation of devices sensors and actuators. The intelligent systems through these get information and achieve reactions to real world [7]. The Smart devices are products and can easily programmed through an interface, a network connectivity, an application and give the characteristics of smart homes and environments [8]. The evolution of technology, the interconnection, synchronization and coordinated use of different technologies, can help to create an environment that is considered intelligent [9].

\section{Disabled people - Definitions}

According Pirkl J., (1994) disability, restriction or lack (resulting impairment) or ability to perform an activity in the manner or within the range considered normal for a human being. Three factors determine the presence of a disability. Each is a potential barrier limiting a person's freedom and independence: the objective, the ongoing condition results of medical, or injury conditions and the third the discrimination of our environment [10].

Disabled people are a minority in our population. The term disabled includes all the variety of population, people who are at a disadvantage due to an accident due to certain conditions such as pregnancy or even the elderly who become helpless in their old routine, to walk to climb a ladder to be flexible in their social life. While the percentage of mobile disabled people is much higher than what is officially shaken by the world health 
organization. About $15 \%$ of the global population, i.e. about 650 million people, have disabilities [11], [12].

For consistency reasons, we define disability according to the International Classification of Functioning, Disability and Health (ICF) of the World Health Organization, attributing to disability as a complex concept with multiple dimensions [13].

It is "the umbrella term for impairments, activity limitations and participation restrictions, referring to the negative aspects of the interaction between an individual (with a health condition) and that individual's contextual factors (environmental and personal factors)" [14].

The term handicap refers to the inability of a person to access a set of barriers, coming from the structured environment and limit his ability to be active in social areas such as information, communication, education, e.tc. With the term (handicap) therefore emphasizes the inadequacies of the environment in which the individual lives and that prevent him from participating equally in the life of society [15]. According to the WHO, the cause is the damage (impairment) that has been caused, which can be physical, mental or otherwise, the result is disability in relation to the ability-normal in action and performance. There may be disability (physical, mental), to create disability always in relation to what is socially acceptable, but what leads to disability is the design of object function spaces in a way that gives the definition and percentage of social disability. A more careful approach, the WHO concluded that disability is the result of the relationship between an individual's abilities and the requirements of the environment. If the performance of the individual in the seven basic categories: (sight, hearing, communication, mental functions, movement, dexterity and stretching / reaching), fall short of his abilities, then the structured environment renders the individual helpless and prevents him from integrate equally into society. With this perception we lead to social disability created by social and environmental factors, various conditions, or mechanisms, deficiencies or imperfections of the environment [16]. A disability exists only when the degree and type of impairment cause difficulties in a certain environment with particular activity or capacity demands, such as in the work environment [17].

\section{Disabled -Technology and Smart Applications}

We try to improve the quality of life of All and especially people with cognitive kinetic or visual disabilities through technology [18]. To succeed in that we have to ensure proper living conditions providing their autonomy security and supporting their socially connection. As everybody personal social life is diverted in outside and insight of its house [19]. The wheelchair is one of the most commonly used assistive devices for improving personal mobility, which is not a tool is their legs is the condition for living in dignity. For people with kinetic problems wheelchair is the connection between the insight of their house and outside of it [20]. It is a shame for our society for the governments for people who work in research and support human rights to know that in our time $10 \%$ of disabled require a wheelchair. In 2003, it was estimated that more than 20 million of those requiring a wheelchair for mobility did not have one. Several systems with the support of technology, of smart applications, present that successful integration in many sectors of their daily life [21]. From the perspective of the Information Technology (IT) professional, the process of designing and developing for an inclusive information society requires awareness and to-the-point guidance with respect to these 
design-for-all tools [22]. For people with mild cognitive disabilities ensuring their daily pharmaceutical dosage or the ability to follow a daily schedule is very important for their personal independence. According (J. Haupert et al.2011) is provided the technical infrastructure such as the universal control hub or the digital product memory. Our longterm vision is to promote an accessible intelligent environment based on open standards and architectures and innovative solutions where everyone can continue to play a role in society [23]. In order the disabled people to be accepted in our society it is more important to be adapted in the word with the help of smart technology. They must be integrated in smart technology [24].

Although the access is usually addressed to people with sensory disabilities such as visual or listening impairment, or kinetic disabilities, there are also projects financial supported from the European Union that improve the lives of people with Intellectual or Development Disabilities (IDD). The Information Communication Technology (ICT) tools as mobile apps can improve their daily duties helping them to interact with the information society [25]. People with severe cerebral palsy and brain injury are often quadriplegic and computer and assistive technology is a great help for them [26]. Smart environments and interfaces systems help children with physical or learning disabilities, long-term care facilities for people with advanced neurological diseases, hospitals, and private homes [27]. There are devices which are important for everyday safety for people with motion impairments as reported by Javagopi et al (2009). Some examples of what we know and encounter in their daily lives are: A binary switch, a pull string, a mechanical touch, such as a hit plate, a tremble stick. It can also be an electrical switch, such as a voice-activated switch if the person can control making a sound, a tonguemovement detector, or a motion-sensitive photocell or infrared switch. These switches allow users with some motor control to operate wheelchairs or activate selection commands in assistive software [28].

One of the characteristics of the world-wide-web world is how has qualified the ordinary people to live in that digital revolution in a new way of live providing innovations to education entertainment and shopping [29]. Ordinary people utilize appliances with sensors and actuators during their daily life [30]. By coordinating the actions of networked devices or services, it is possible for the environment to behave in a holistic and reactive manner to satisfy the occupants needs; creating an intelligent environment [31].

Disrupting the used home appliances into sets supported by network accessible services it is possible to disrupt the appliance of our everyday life or to create new one combining network services and finally to create a new one called virtual appliance [32]. This principle can be extended to decompose and re-compose software applications allowing users to create their own bespoke applications [31]. Collectively, such user created entities are referred to as Meta - appliances or - applications, more generally abbreviated to Maps [33]. Deconstruction and user customized MAps raise exciting possibilities for occupants of future intelligent environments, and sets significant research challenges [34].

\section{Conclusion and Future}

It is necessary to believe that a Smart City has to be anthropocentric and to require from its citizens to participate to the design prosses, to realize the vision, to participate to take an active part in the realization of all plans. It is important to understand the severe 
problems of our planet the importance of the unique human being and to use technology in a proper way friendly to the environment and the people.

Smart Cities need to be designed to allow the inclusion of all kinds of citizens. Motor disabled people like wheelchair users, blind people who may have problems to interact with the city. Internet of Things (IoT), technologies provide the tools to include all citizens in the Smart City context. Using Augmented Reality and Internet of Things we can improve accessibility of people with motor disabilities in the context of Smart Cities. To improve processes using technology we connect people with physical objects, information systems and among themselves. We improve the relation between the citizens and their context. We promote independence, equal opportunities and human rights.

\section{References}

[1] C. Troussas, A. Krouska, \& C. Sgouropoulou, Impact of social networking for advancing learners, knowledge in E-learning environments, Educ Inf Technol $2021 \mathrm{https}: / /$ doi.org/10.1007/s10639-02110483-6]

[2] D. Washburn, U. Sindhu, Helping CIOs Understand Smart City Initiatives. Forrester Research, 2010

[3] C. Papakostas, C. Troussas, A. Krouska, C. Sgouropoulou. User acceptance of augmented reality welding simulator in engineering training. Educ Inf Technol, $2021 \mathrm{https} / / / \mathrm{doi} . o r g / 10.1007 / \mathrm{s} 10639-020-10418-7$

[4] C.Troussas, C. Sgouropoulou: Innovative Trends in Personalized Software Engineering and Information Systems - The Case of Intelligent and Adaptive E-learning Systems. Frontiers in Artificial Intelligence and Applications 324, IOS Press 2020, ISBN 978-1-64368-096-5, pp. 1-96

[5] C. Troussas, A. Krouska, F. Giannakas, C. Sgouropoulou, I. Voyiatzis: Redesigning teaching strategies through an information filtering system. PCI 2020-24th Pan-Hellenic Conference on Informatics, November 2020, Pages 111-114. https://doi.org/10.1145/3437120.3437287

[6] C. Troussas, A. Krouska, C. Sgouropoulou, I. Voyiatzis: Ensemble Learning Using Fuzzy Weights to Improve Learning Style Identification for Adapted Instructional Routines. Entropy 22(7): 735, 2020

[7] C. Troussas, A Krouska, C. Sgouropoulou: Collaboration and fuzzy-modeled personalization for mobile game-based learning in higher education. Computers \& Education, (2020), p144

[8] A. Krouska, C. Troussas, C. Sgouropoulou, Applying Genetic Algorithms for Recommending Adequate Competitors in Mobile Game-Based Learning Environments. In: Kumar V., Troussas C. (eds) Intelligent Tutoring Systems. ITS 2020. Lecture Notes in Computer Science, vol 12149. Springer, Cham, 2020 https://doi.org/10.1007/978-3-030-49663-0_23

[9] U. Gretzel, L. Zhong, C. Koo, Application of smart tourism to cities. International Journal of Tourism, 2016

[10] J. Pirkl, Trangenerational design. Van Nostrand Reinhold, New York, (1994), Pp73

[11] World Helath Organization Fact sheet on wheelchairs, October 2010 https://apps.who.int/iris/bitstream/handle/10665/205041/B4616.pdf?sequence=1\&isAllowed=y]

[12] World Health Organization. (2011). World Report on Disability: Summary, 2011. Geneva, Switzerland, 2011 https://apps.who.int/iris/bitstream/handle/10665/205041/B4616.pdf?sequence=1\&isAllowed=y]

[13] World Health Organization. (2001). International Classification of Functioning, Disability and Health (ICF). Geneva, Switzerland, 2001

[14] World Health Organization, World Report on Disability: Summary, 2011. Geneva, Switzerland, 2011

[15] Accessibility http://www.disabled.gr/category/amea-disability-library/access/

[16] A. Vergou, D. Paganopoulou, P. Pelekanou, Degree of user satisfaction from the level of accessibility of public services in the Municipality of Patras, school of health professions and social work department, 2013

[17] K. Vornholt, P. Villotti, B. Muschalla, J. Bauer, A. Colella, F. Zijlstra, G. Van Ruitenbeek, S. Uitdewilligen \& M. Corbière, Disability and employment - overview and highlights, European Journal of Work and Organizational Psychology, 2017 doi: 10.1080/1359432X.2017.1387536

[18] M. Poli, Greece, Tourism and Disability, Strategic Innovative Marketing and Tourism, International Journal of Strategic Innovative Marketing 8th ICSIMAT, Springer, 2019 https://doi.org/10.1007/978-3030-36126-6_74]. 
[19] A. Krouska, C. Troussas, C. Sgouropoulou: A Personalized Brain-Based Quiz Game for Improving Students' Cognitive Functions. BFAL 2020, p102-106

[20] World Health Organization Fact sheet on wheelchairs, Wheelchairs assist people with disabilities to become productive members of their communities, https://apps.who.int/iris/bitstream/handle/10665/205041/B4616.pdf, October 2010

[21] C. Troussas, F. Giannakas, C. Sgouropoulou \& I. Voyiatzis (2020) Collaborative activities recommendation based on students' collaborative learning styles using ANN and WSM, Interactive Learning Environments, 2020 doi:10.1080/10494820.2020.1761835

[22] P. Koutsabasis1, J. S. Darzentas, T. Spyrou, A. Velasco, Y. Mohamad, J. Darzentas, Towards an Environment that Supports Internet Design for All, Conference paper, 2001

[23] R. Neßelrath, J. Haupert, J. Frey, B. Brandherm, Supporting Persons with Special Needs in their Daily Life in a Smart Home, IEEE, 2011 doi: 10.1109/IE.2011.75

[24] C. Troussas, A. Krouska, C. Sgouropoulou, (2020) Dynamic Detection of Learning Modalities Using Fuzzy Logic in Students' Interaction Activities. In: Kumar V., Troussas C. (eds) Intelligent Tutoring Systems. ITS 2020. Lecture Notes in Computer Science, vol 12149. Springer, Cham, 2020 https://doi.org/10.1007/978-3-030-49663-0_24

[25] J. Dekelver, J. Daems, S. Solberg, N. Bosch, L. Van de Perre, A. De Vliegher, T. More, A digital travel assistant for people with intellectual disabilities: Modeling and design using contemporary intelligent technologies as a support for independent traveling of people with intellectual disabilities, 2015 doi: 10.1109/IISA.2015.7388014

[26] M.Poli, Covid-19 Effects in People's Daily Life, Social Media's Role and the Power of Emotions and State of Mind, International Journal of Strategic Innovative Marketing 9th ICSIMAT, Athens, Greece, Springer, 2020 https://doi.org/10.1007/978-3-030-66154-0

[27] B. Margrit, Intelligent Interfaces to Empower People with Disabilities, Handbook of Ambient Intelligence and Smart Environments, Springer, 2010 pp 409-432

[28] D Jayagopi, H. Hung, C. Yeo, D. Gatica-Perez, (2009) Modeling dominance in group conversations using nonverbal activity cues. IEEE Trans. on Audio, Speech, and Language Processing, Special Issue on Multimodal Processing for Speech-based Interactions, March (2009) Vol. 17, No. 3, pp. 501-513

[29] C. Troussas, A. Krouska, C. Sgouropoulou, Towards a Reference Model to Ensure the Quality of Massive Open Online Courses and E-Learning. In: Frasson C., Bamidis P., Vlamos P. (eds) Brain Function Assessment in Learning. BFAL 2020. Lecture Notes in Computer Science, vol 12462. Springer, Cham., 2020 https://doi.org/10.1007/978-3-030-60735-7_18

[30] A. Krouska, C.Troussas, C. Sgouropoulou: Usability and Educational Affordance of Web 2.0 tools from Teachers' Perspectives. PCI 2020-24th Pan-Hellenic Conference on Informatics, November (2020), Pp 107-110. https://doi.org/10.1145/3437120.3437286

[31] J. Chin, V. Callaghan and G. Clarke, End-user Customisation of Intelligent Environments, Handbook of Ambient Intelligence and Smart Environments, 2010, p 370, Springer

[32] C. Papakostas, C. Troussas, A. Krouska, C. Sgouropoulou, Exploration of Augmented Reality in Spatial Abilities Training: A Systematic Literature Review for the Last Decade, Informatics in Education, 20(2021), no. 1, 107-130, doi 10.15388/infedu.2021.06

[33] J. Chin, V. Callaghan and G. Clarke, End-user Customisation of Intelligent Environments, Handbook of Ambient Intelligence and Smart Environments, Springer, (2010), p 372

[34] J. Chin, V. Callaghan, G. Clarke, Soft-appliances: A vision for user created networked appliances in digital homes, Journal of Ambient Intelligence and Smart Environments 1, IOS Press, (2009), 65-71, doi 10.3233/AIS-2009-0010, 